\title{
The Understanding of the Model of Microcosm in Primary and Secondary Education
}

\author{
Ourania Gikopoulou \\ National and Kapodistrian University of Athens, Greece
}

\begin{abstract}
Studies have shown that students face difficulties in understanding the scientific explanations of the physical phenomena. We argue that this is the case because they are constrained by their initial explanatory frameworks which are based on their everyday experiences and differ significantly from the scientific ones. The understanding of the scientific concepts is facilitated by the use of appropriate models and we support that the unifying model of microcosm can facilitate the learning process. This research focuses on whether students of primary and secondary education are able to understand the microscopic model and use it to explain the macroscopic phenomena. In bibliography it is supported that this model can help students approach phenomena about which they lack supervision, e.g. invisible gases, therefore a great deal of effort is spent worldwide to find the best educational approach of microcosm for students of as younger age as possible. The results suggest that students of this age are able to understand the microscopic model and this model facilitates their understanding of the macroscopic phenomena. Our research adds to previous studies exploring the ways of improving the learning process and facilitating the understanding of the scientific concepts.
\end{abstract}

\section{Introduction}

In the last decades it is observed internationally a continuous interest about the model of microcosm and its best educational approach. This interest is constantly growing also due to the constant discoveries of famous research centers such as the European Organization for Nuclear Research (CERN).

The model of microcosm (or microscopic model) refers to the invisible particles that consist matter in all of its forms (solids, liquids, gasses) and the diversity of our world as well as to their constant movements.

Many studies have shown that students face considerable difficulties in understanding the scientific explanations about the macroscopic phenomena [3] [9] [12] [13] [15] [16] [20]. For example, they do not understand boiling or evaporation because they confuse vapour with air; they consider water as exclusively liquid; they think that matter is static and continuous; they do not realize that the macroscopic properties of matter result from its microscopic structure which affects their understanding of the physical changes of matter.

We argue that students' difficulties stem from the fact that they form initial explanatory frameworks for matter based on their everyday observations [5]. Their understanding of the scientific concepts is constrained by these explanatory frameworks which provide them with explanations about the phenomena, but differ significantly from the scientific ones, therefore can be an obstacle in the learning process. These initial explanatory frameworks gradually evolve through the creation of alternative frameworks, until the scientific model is adopted.

According to the framework theory proposed by Vosniadou and as shown by relevant studies [17] [18], some concepts are difficult understood by the students because they violate basic principles of their initial framework. When students are exposed to the scientific explanations, they attempt to incorporate the new inconsistent information into their existing framework, but this incompatibility may lead to misunderstandings and the creation of alternative frameworks.

Namely for the concept of matter according to the students' explanatory framework [8] [20] matter is perceived by the senses, substances are continuous and their identity is determined by their appearance and physical state.

On the other hand, according to the scientific framework [6] [7] [8] matter is conceived as basic component that has weight and occupies space, matter is maintained during its transformations, material bodies consist of invisible particles that are in constant motion and their identity is determined by objective and measurable properties of matter. Moreover, the physical states of matter are described by means of the molecules and the change of state is explained by changes in the forces between molecules.

Therefore it is supported that a series of changes is necessary to bridge the gap between the initial students' understanding of matter and the scientific 
particulate theory [20]. Students should make the distinction between the perceived with the senses and the physical properties of matter and understand how they relate to each other.

In other words, the understanding of the scientific concepts demands the reconstruction of students' initial explanatory framework which is aided by the use of appropriate models. We support that the unifying approach of the model of microcosm can be such a model facilitating the learning process and optimizing the understanding of macroscopic phenomena.

Previous studies have shown that the educational model of microcosm is a valuable tool for understanding the scientific concepts and explaining the macroscopic phenomena, therefore it is observed a continuous effort internationally to record the best educational approach of this model of microcosm or, as reported more often, of the particulate nature of matter.

In 1960s already the Nobel laureate physicist Richard Feynman emphasizes the importance of this model for science, while in the literature is widely expressed that the particulate theory is one of the most important modern scientific theories, consisting of a few simple basic principles and offering precise and elegant explanations for all the macroscopic phenomena.

However, the introduction of the particulate theory to education seems to be a difficult and longterm issue, therefore a great deal of effort is spent worldwide to find the best educational approach of microcosm for students of as younger age as possible. In bibliography it is put forward that it is of great importance for students to comprehend the particulate theory so as they approach several branches of science [2]. It is also supported that this model can help students approach phenomena about which they lack supervision, e.g. invisible gases [6].

Certainly, the difficulties that students -especially of younger ages- confront at their attempt to comprehend the particulate model are taken into serious account. The basic difficulties regarding the microscopic model is that it is a model and not a real object and it is of a scale that students are unable to comprehend through their senses. Many students do not consider particles as the basic components of matter but as something in matter, as embedded in it [9], [13]. This is an extremely strong misconception that persists even after university teaching. For students matter appears to be continuous so it is continuous [5], [8], [12]. The model of the particles within the material is an alternative model, which is created as students attempt to incorporate the school information into their intuitive idea that matter is continuous.

Other studies argue that the existence of alternative concepts at the macroscopic level is related with difficulties in the understanding of particle theory as an interpretative model. Students who understood how the particles explain some macroscopic phenomena had also understood the macroscopic concept of matter, weight, volume and density [15].

Moreover, Wiser and Smith [20] support that the path to the scientific theory of matter involves changes in a wide network of concepts the extent of which has not been appreciated enough by the educational community.

Coming to the case of Greece, there are encouraging results about considering the particulate model an achievable didactical goal for young students and it is stated that an early version of particulate model that explains physical changes, seems to be suitable for students of primary education even from the age of nine and on [14]. The particulate nature of matter emerges as a fundamental concept for science and it is supported that even primary school students are able to understand the model of the microcosm, since they can handle the concepts of this model satisfactorily after the teaching intervention.

To sum up, researchers seem to have come to an agreement concerning the development of a simple microscopic model early by the students, which will guide them later to a more complicated sub-atomic model [2], [11]. Furthermore, the comprehension of a basic particulate model by the students appears to be a presupposition for them to approach the structure of the atom that is taught later. According to Eshach \& Fried [4] science of early school years is an effective framework for scientific thought to be evolved and is expected to contribute to the formation of the groundwork on which the comprehension of difficult scientific concepts will be based so as they are approached later on in a more typical manner.

We also argue that an approach that can facilitate the learning process and optimize the understanding of the macroscopic phenomena is the model of microcosm, which can also facilitate the optimal unification of all the thematic units of science.

Taking into consideration the international research concerning the introduction of the model of microcosm at secondary or even at primary education, we examine whether it is feasible for students of these ages to understand and effectively use it for the interpretation of the macroscopic phenomena.

\section{Research: Questions, Method, Hypotheses}

Contributing to the scientific debate around these issues our research question focuses on exploring whether students of junior high school or even of primary school are able to comprehend the processes 
of microcosm and use this model effectively to explain the macroscopic phenomena.

For the collection of data we used the written documents and sketches of the students who participated in the relevant National Physics Contests. We recorded and analyzed participants' answers to questions demanding microscopic explanations of the phenomena and we categorized them based on their completeness, clarity and scientific excellence.

The statistical analyses of the results helped us draw conclusions and suggestions on the feasibility and effectiveness of the use of the microcosm model for the interpretation of the phenomena of the macrocosm by the students of these levels.

Our basic hypothesis was that students of junior high school, even of primary school, are able to understand the microscopic model and use it to explain the macroscopic phenomena.

A second hypothesis was that there is a correlation between students' understanding of the model of microcosm and their explanations of the macroscopic phenomena. We expected that students who have acquired a better understanding of the microscopic model will also face fewer difficulties in the understanding of the macroscopic phenomena.

\section{The Research in Secondary Education}

Since the model of microcosm is not used systematically in the two last grades of high school in Greece, our research was limited to the $7^{\text {th }}$ graders (13 years old).

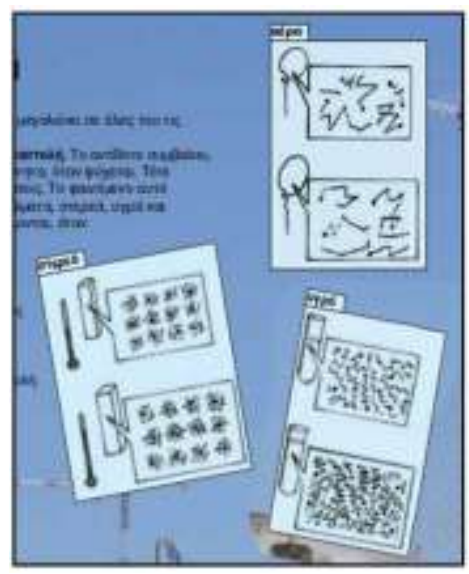

Figure 1. Static captures of a solid, a liquid and a gas at two different temperatures from the textbook

At this grade the official science textbook [7] covers several topics: measurements, heat, temperature, thermal equilibrium, changes of state, expansion and contractionn, light, electricity and electromagnetism. This book has a small appendix named "microcosm explains macrocosm" which describes briefly the microscopic processes presenting also static captures.
Our sample consisted of 1018 students of $7^{\text {th }}$ grade (13 years old) from different schools, both public and private, across all the country (Greece) who participated in the National High School Physics Contest 2015. All the written documents of the Physics Contest with the students' answers were collected at the University of Athens and examined.

The University of Athens organizes this National Physics Contest each year for all high school grades as well as the $5^{\text {th }}$ and $6^{\text {th }}$ grade of primary school.

The last topic of the competition of this year, consisting of two questions, asked students to describe microscopically (in written and with sketches), and compare with each other: a) a liquid at two different temperatures (cold; hot) and b) a solid at two different temperatures (lower temperature; higher temperature).

Specifically, the first question was: "Describe and compare the movements of the molecules of the hot water with the movements of the molecules of the cold water at the beginning of the experiment." (At the beginning of the experiment described in the previous topic, the students put on a desk a bowl containing cold water and then in this blow they place a pot with hot water).

And the second question was: "Draw two snapshots that show the positions, distances and tracks of the movement of the molecules of the material from which the bowl is manufactured at two different temperatures (higher and lower). Provide explanations of your sketches".

The other topics of the competition, which are not addressed directly in this investigation, referred to temperature and its measurement as well as the thermal balance and the ways of heat transmission. These issues are not addressed directly, but we investigated the correlation between students' understanding of the model of microcosm and their explanations of these phenomena, according to our second hypothesis. We hypothesized that students who have acquired a better understanding of the microscopic model will also be able to explain the macroscopic phenomena more sufficiently.

\subsection{Results}

Based on their answers to the two questions of the last topic of the competition the students were categorized into four basic categories of explanations: Initial, Alternative, Correct and Complete.

The criteria we used to categorize students' answers to both questions were: whether they just describe the process or give some kind of explanation, whether the explanation they give is correct or contains errors and misunderstandings, whether their explanation is macroscopic or microscopic, what they say about the random movements of molecules at lower and higher 
temperatures, and especially if they accept that these are the same molecules and whether their sketches are particulate or continuous.

Based on these criteria we distinguish for each case (heating liquid, heating solid) the four types of explanations described below.

a) Initial explanation: they simply describe the phenomenon without explaining it or their description is based on the time sequence (e.g. cold water is heated and hot water is cooled, when water is heated its temperature rises etc.). They don't seem to understand the process, nor consider it necessary to give an explanation. They also don't draw a sketch or their sketch has no reference to the molecules. Some characteristic examples of students' initial answers are:

- The temperature of the hot water decreases and the temperature of the cold water increases.

- When the pot with the hot water is placed into the bowl with the cold water, the hot water is cooled and the cold water is heated.

b) Alternative explanation: They give some kind of explanation (at macroscopic or microscopic level) but their explanation contains errors and misunderstandings (e.g. expansion and contraction of molecules, hot molecules-cold molecules etc.). They mention erroneous procedures or transfer macroscopic properties of matter into the microcosm. Their sketches present continuous or microscopic patterns without displaying the molecules in a consistent way. Some characteristic examples of students' alternative answers are:

- The cold water absorbs the molecules of the hot water.

- Molecules are transferred from the pot into the bowl.

- The hot water contains hot molecules whereas the cold water contains cold molecules.

- At the lower temperature the molecules contract and the higher temperature they expand.

- At the higher temperature there are more molecules.

- At the lower temperature molecules do not move at all.

- At the lower temperature the molecules are glued all together.

- At the lower temperature the molecules occupy a very small part of the body, while at the higher temperature they occupy about half the body.

- At the lower temperature the molecules make circular rotations and at the higher temperature the molecules move in straight lines.

- At lower temperature the molecules move counterclockwise and at higher temperature they move clockwise.

- The molecules move inside the water.

c) Correct explanation: They give a proper scientific explanation which describes the basic information about the movements or the distances of molecules but not for the whole process: the positions, distances and tracks of the movements of molecules. They draw microscopic sketches without many details concerning the movements of molecules or the distances between them.

d) Complete explanation: They give a complete scientific explanation which describes the positions, distances and tracks of the movements of molecules (e.g. when the temperature of the solid increases, the speed of the molecules and their distances from their permanent positions grows).

As shown at Table 1, some students gave alternative explanations for liquids $(21 \%)$ and solids (24\%) whereas the great majority of students was able to give scientific microscopic explanations for liquids $(68 \%)$ as well as solids $(65 \%)$, with $26 \%$ and $25 \%$ respectively providing complete microscopic explanations, with details about the movements, the distances and the tracks of molecules.

These data seem to confirm our first hypothesis concerning the understanding of the microscopic model by students of this age.

Table 1. Students' explanations about heating liquid and heating solid (frequency and percentage)

\begin{tabular}{|l|c|c|}
\hline Explanation & Liquid & Solid \\
\hline No answer & $35(3 \%)$ & $44(4 \%)$ \\
\hline Initial & $82(8 \%)$ & $73(7 \%)$ \\
\hline Alternative & $217(21 \%)$ & $242(24 \%)$ \\
\hline $\begin{array}{l}\text { Correct } \\
\text { microscopic }\end{array}$ & $425(42 \%)$ & $411(40 \%)$ \\
\hline $\begin{array}{l}\text { Complete } \\
\text { microscopic }\end{array}$ & $259(26 \%)$ & $248(25 \%)$ \\
\hline Total & $1018(100 \%)$ & $1018(100 \%)$ \\
\hline
\end{tabular}

With regard to students' sketches they were categorized into three basic categories: continuous, microscopic with mistakes and microscopic correct.

Table 2. Categorization of Students' sketches (frequency and percentage)

\begin{tabular}{|l|c|}
\hline Students' Sketches & \\
\hline No answer & $42(4 \%)$ \\
\hline Continuous & $90(9 \%)$ \\
\hline Microscopic with mistakes & $207(20 \%)$ \\
\hline Microscopic correct & $679(67 \%)$ \\
\hline Total & $1018(100 \%)$ \\
\hline
\end{tabular}

As shown at Table 2, the great majority of students $(67 \%)$ drew correct microscopic sketches, $20 \%$ of them made sketches microscopic with mistakes and only $9 \%$ of them drew continuous sketches, without any reference to molecules. 
Some characteristic examples of students' sketches in each category (continuous, microscopic with mistakes, microscopic correct) are presented at the Figures 2, 3 and 4.

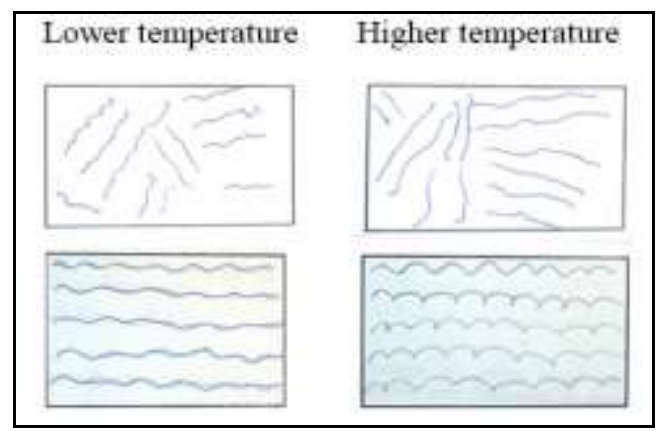

Figures 2. Examples of students' continuous sketches

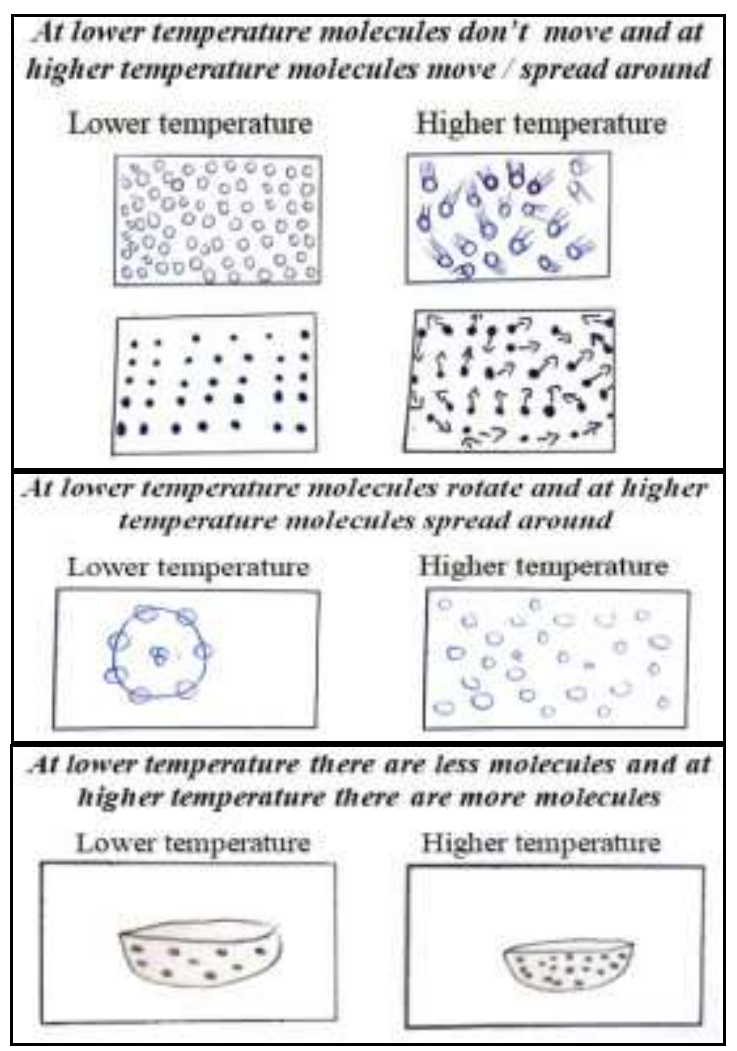

Additionally, in order to test our second hypothesis, we examined the correlation between students' understanding of the model of microcosm (through their explanations about the heating liquids and solids) and their explanations of the macroscopic phenomena (through their total performance in the contest).

We calculated students' total performance based on their answers to the other questions of the competition about the macroscopic phenomena. We divided the performance into 5 groups based on the score: 0-20. 20-40, 40-60, 60-80 and 80-100.

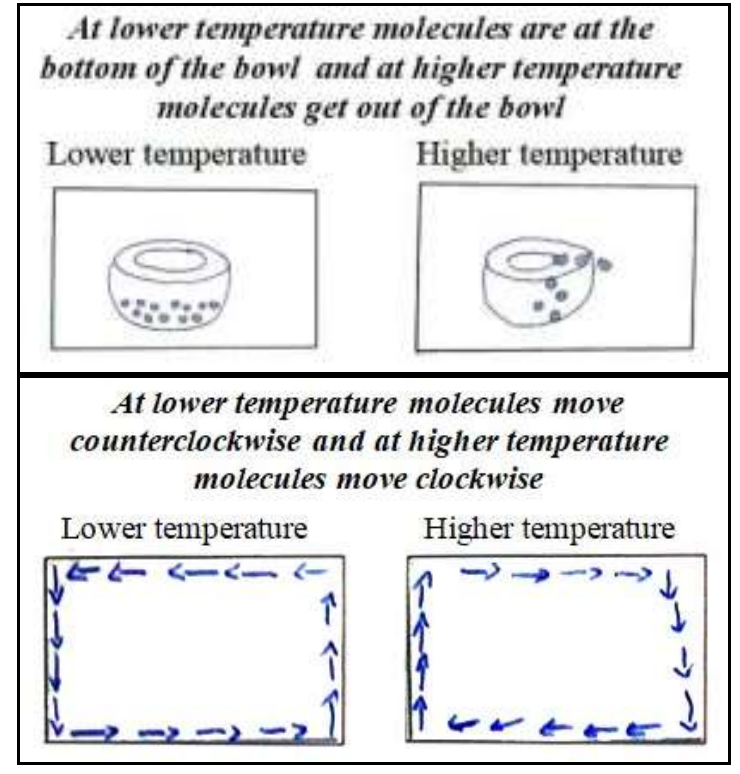

Figures 3. Examples of students' microscopic with mistakes sketches

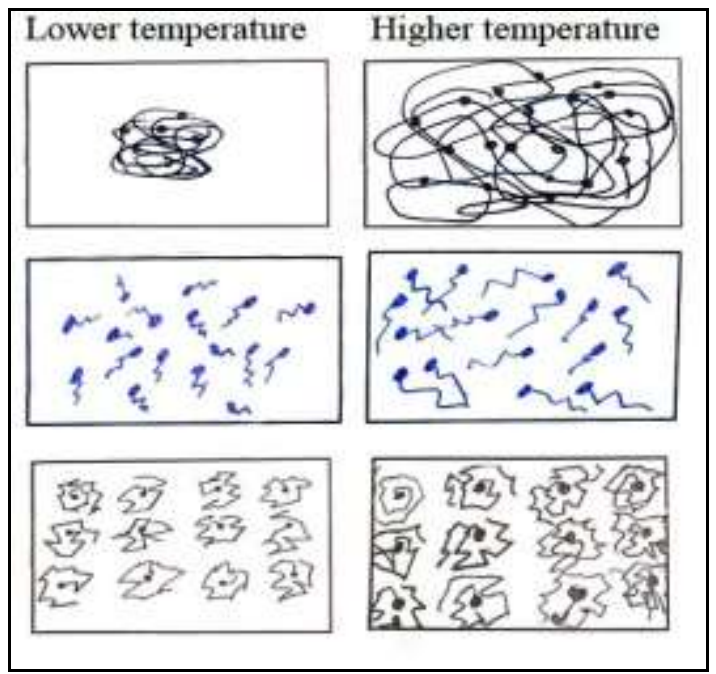

Figures 4. Examples of students' microscopic correct sketches

According to our theoretical framework, we expected that students who do not understand the microscopic model and give initial or alternative explanations about solids and liquids will face greater difficulties in the explanation of the macroscopic phenomena and therefore achieve lower score in their total performance in comparison to the students whose explanations are in accordance with the microscopic model.

The results seem to confirm our hypothesis, since Pearson $\mathrm{R}$ Correlation Coefficient that was calculated showed high degree of correlation between students' microscopic explanations and their performance in the macroscopic explanations, as shown in Table 3. 
Table 3. Correlations between students' total performance and their microscopic explanations about solids and liquids calculated with Pearson R correlation Coefficient

\begin{tabular}{|l|l|c|c|}
\hline & & $\begin{array}{c}\text { Explanation } \\
\text { of liquids }\end{array}$ & $\begin{array}{c}\text { Explanation } \\
\text { of solids }\end{array}$ \\
\hline \multirow{2}{*}{$\begin{array}{l}\text { Total } \\
\text { perfor } \\
\text { mance }\end{array}$} & \begin{tabular}{l} 
Pearson \\
\cline { 2 - 4 }
\end{tabular} &, $865^{* *}$ &, $837^{* *}$ \\
\hline & Nig. &, 000 &, 000 \\
\hline
\end{tabular}

**. Correlation is significant at the 0.01 level (2-tailed).

These results can be seen more clearly in the following Table 4, correlating participants' explanations of heating liquid and their total performance, where the results are more obvious. Similar results are observed for the explanations of heating solid.

Table 4. Correlations between students' microscopic explanations of liquid and total performance on macroscopic explanations

\begin{tabular}{|l|r|r|r|r|r|}
\hline & \multicolumn{5}{|c|}{ Total performance } \\
\hline $\begin{array}{l}\text { Explanation } \\
\text { of liquid }\end{array}$ & $0-20$ & $20-40$ & $40-60$ & $60-80$ & $80-100$ \\
\hline No answer & $\mathbf{2 8}$ & $\mathbf{6}$ & 1 & 0 & 0 \\
\hline Initial & $\mathbf{5 1}$ & $\mathbf{2 9}$ & 2 & 0 & 0 \\
\hline Alternative & $\mathbf{4 0}$ & $\mathbf{1 6 1}$ & $\mathbf{1 6}$ & 0 & 0 \\
\hline Correct & 0 & 0 & $\mathbf{2 9 5}$ & $\mathbf{1 1 7}$ & $\mathbf{1 3}$ \\
\hline Complete & 0 & 0 & 7 & $\mathbf{1 5 8}$ & $\mathbf{9 4}$ \\
\hline Total & 119 & 196 & 321 & 275 & 107 \\
\hline
\end{tabular}

All the students who gave correct and complete microscopic explanations also achieved higher score (80-100) at their total performance (in explaining the macroscopic phenomena), whereas all the students with initial explanations and almost all students with alternative explanations achieved also lower score (0-20 or 20-40) at their total performance (in explaining the macroscopic phenomena).

The results of this study seem to support our hypothesis that students of this age are able to understand the microscopic model and use it to explain the macroscopic phenomena, since the majority of students provided correct or complete microscopic explanations and sketches.

These results triggered us to investigate whether this is the case also for younger students of primary school.

\section{The Research in Primary Education}

The Greek curriculum of Science for the Primary Education aims to systematically introduce the students to the basic concepts of science as well as the way of studying the phenomena of our world. The official science textbooks for the $5^{\text {th }}$ and the $6^{\text {th }}$ grade [1] attempt to introduce the model of microcosm for the interpretation of the macroscopic phenomena and the unification of the thematic units. This microscopic approach, as shown at Figure 5, is presented in its simplest possible educational approach with simple references and static captures (without the use of mathematics) but without oversimplifications, which usually create misconceptions, often irreversible in later studies. The application of this model is not quite compulsory as it is at the discretion of the teacher and depends also on the learning level of students.

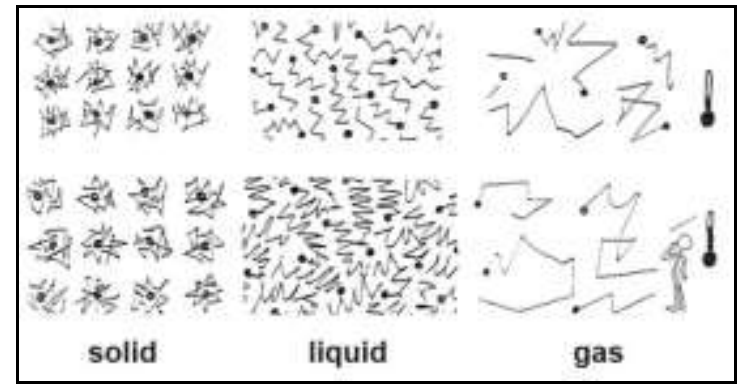

Figure 5. Example of static captures of a solid, a liquid and a gas at two different temperatures from the textbooks

However, in spite of the intentions of the books and the material provided, in practice it has been proved that the exploitation of the model of microcosm is not adequate in class. Often the reference to the microscopic model is either superficial and non-systematic, or completely omitted, as teachers believe it may be difficult for students.

Moreover, in 2011, the instructions from the Pedagogical Institute and the Ministry of Education suggested that the references to the microcosm from the student book should not be used at all during the class, without providing any justification for this suggestion or any reference to relevant researches. This instruction applied until the school year 20142015, when the new directives of the Institute for Educational Policy and the Ministry of Education no longer referred to the non-teaching of the model of microcosm.

Given the fact that during the school year 20122013 the Ministry deterred the exploitation of the model of microcosm in the 5th and 6th grade, coupled with the fact that the questions of the National Primary School Physics Contest 2013 did not require microscopic explanations, we were pleasantly surprised when we noticed that several students actually used this model in their answers!

Our sample consisted of 1654 students of $5^{\text {th }}$ grade (10 years old) from different schools, both public and private, across all the country (Greece) who participated in the National Primary School Physics Contest 2013.

All the written documents of the Physics Contest with the students' answers were collected at the 
University of Athens (that organizes the Contests) and examined.

One of the topics of the Contest of this year asked students to explain the differences in the properties of ice, water and water vapor. More specifically the question was: "What are the differences in the properties of ice, water and water vapor? Can you explain them?

a) Ice, which is a solid,...

b) Water, which is a liquid, ...

c) Water vapor, which is a gas, ..."

The formulation of this topic did not require microscopic explanation, since students' responses could be based only on the macroscopic properties of solids, liquids and gasses as taught in this grade. However, we found out that many students gave microscopic explanation and referred to the distances and movements of the molecules in the three different physical states. Therefore it was decided to give bonus points (from 1 to 3 points depending on the details and the completeness of their answers) to these students.

The other topics of the Contest referred to the description of phenomena and processes such as melting, coagulation, evaporation, boiling, liquefaction as well as the water cycle and its significance for the environment. These topics are not addressed directly, but we investigated the correlation between students' understanding of the model of microcosm and their explanations of these phenomena, according to our second hypothesis.

\subsection{Results}

The results showed that a significant percentage of students, $45 \%$, almost half of them (744 students in a total of 1654), answered this question using the model of microcosm in a satisfactory way making references to the movements and distances of the particles in the three states of matter, even though they were not asked to do so.

Table 5. Students' categorization based on the bonus points they received (frequency and percentage)

\begin{tabular}{|c|c|}
\hline $\begin{array}{c}\text { Bonus points for } \\
\text { microscopic explanation }\end{array}$ & \\
\hline 0 (incorrect) & $9(1 \%)$ \\
\hline 1 (adequate) & $145(20 \%)$ \\
\hline 2 (correct) & $398(54 \%)$ \\
\hline 3 (complete) & $192(25 \%)$ \\
\hline Total & $744(100 \%)$ \\
\hline
\end{tabular}

Table 5 shows the bonus points of the students who answered microscopically, based on the completeness of their answers. The 79\% of the students who provided microscopic explanations gave correct and complete answers, so they received 3 bonus points. A $20 \%$ gave adequate microscopic explanations but without details, so they received 1 bonus point. Finally, few students (1\%) gave incorrect microscopic explanation and therefore they did not receive any bonus point.

The following graph summarizes the distribution of students based on the type of explanation they gave to this topic: macroscopic or microscopic.

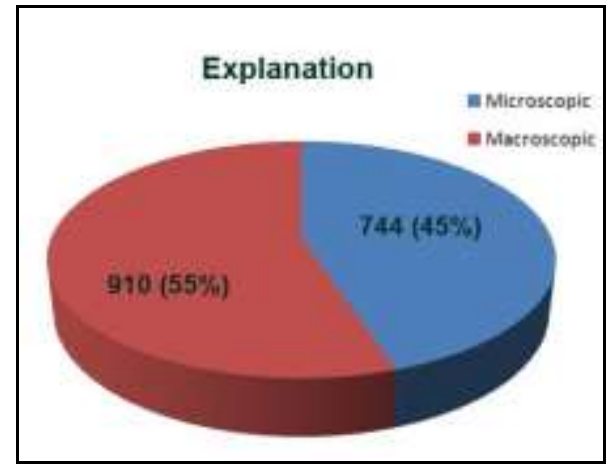

Graph 1. Students' categorization based on their explanations (frequency and percentage)

As shown in the graph, $744(45 \%)$ students gave microscopic explanations to the topic and some typical answers of these students (and their bonus points) are presented below.

a) About the solids / ice:

- The ice molecules move differently from the water molecules and the vapor molecules (1 bonus point)

- The movements of the ice molecules are slower than the liquid and even slower than the gas (2 bonus points)

- The molecules of the solids are closer to one another, therefore solids don't change shape like the liquids (2 bonus points)

- The molecules of ice move towards all directions slower than the molecules of water and they do not approach or move away a lot (3 bonus points)

- The molecules move constantly around permanent positions so they do not move away or come too close to each other ( 3 bonus points)

b) About the liquids / water

- The molecules of the liquids are close, but not as close as the molecules of the solids, so we can move when we are in the water ( 2 bonus points)

- A liquids' molecules move more than those of a solid, but they do not move away or come too close (3 bonus points)

- Water molecules change positions with each other but keep fixed distances (3 bonus points)

- Its molecules move constantly freely, but without leaving or approaching each other (3 bonus points)

c) About the gasses / water vapor

- The molecules of a gas move a lot changing positions constantly and moving as far away as possible (2 bonus points) 
- Their molecules move rapidly towards all directions, where they find space ( 2 bonus points)

- Their molecules are far away from each other and move constantly and randomly in all directions (3 bonus points)

- Their molecules do not have specific positions and move as far away as possible (3 bonus points)

- The molecules of gasses occupy all the space provided and move faster than the molecules of the liquids and solids (3 bonus points)

In order to test our second hypothesis that students who have comprehended the model of microcosm are experiencing fewer difficulties in understanding the scientific explanations of the physical phenomena, we examined the correlation between the microscopic explanations of students and their overall performance on Contest.

We calculated students' total performance based on their answers to the other questions of the competition about the macroscopic phenomena. We divided the performance into 5 groups based on the score: 0-20. 20-40, 40-60, 60-80 and 80-100.

The results seem to confirm our hypothesis, since Pearson $\mathrm{R}$ Correlation Coefficient that was calculated $(0,779)$ showed statistically significant $(\mathrm{p}$ $<0,001)$ correlation between students' microscopic explanations and their total performance, as shown in Table 6.

Table 6. Correlations between students' explanations and total performance

\begin{tabular}{|c|c|c|c|c|c|}
\hline & \multicolumn{5}{|c|}{ Total performance } \\
\cline { 2 - 6 } & $\begin{array}{c}0- \\
20\end{array}$ & $\begin{array}{c}20- \\
40\end{array}$ & $\begin{array}{c}40- \\
60\end{array}$ & $\begin{array}{c}60- \\
80\end{array}$ & $\begin{array}{c}80- \\
100\end{array}$ \\
\hline $\begin{array}{c}\text { macroscopic } \\
\text { explanation }\end{array}$ & 250 & 660 & 0 & 0 & 0 \\
\hline $\begin{array}{c}\text { microscopic } \\
\text { explanation }\end{array}$ & 1 & 81 & 448 & 146 & 68 \\
\hline
\end{tabular}

It is evident that the students who have understood the model of microcosm and use it for their explanations have a higher performance than the other students, i.e. they manage to explain more effectively the macroscopic phenomena of the other topics of the Contest. All the students who gave microscopic explanations also achieved higher score (40-100) at their total performance (in explaining the macroscopic phenomena), whereas all the students with macroscopic explanations achieved also lower score (0-20 or 20-40) at their total performance.

Summarizing the results of this research, we argue that many students of the $5^{\text {th }}$ grade are able to understand the microscopic model and use it to explain the macroscopic phenomena.

Moreover, there is evidence that the understanding of the model of microcosm may be a prerequisite for the understanding of the macroscopic phenomena, but we cannot support it with certainty unless we examine it more thoroughly. This finding is in accordance with our theoretical framework that students who do not understand the microscopic model face greater difficulties in the explanation of the macroscopic phenomena.

\section{Discussion}

The results of our study seem to support our first hypothesis that students of junior high school are able to understand the microscopic model and use it effectively to explain the macroscopic phenomena, since the majority of them provided correct or complete microscopic explanations and sketches.

Similar results but with lower percentages are observed at primary school students. Almost half of them seem able to understand the microscopic model and use it to explain the macroscopic phenomena, providing complete, correct or adequate microscopic explanations.

The results seem to confirm also our second hypothesis concerning the correlation between students' microscopic and macroscopic explanations, since we found that students (both of junior high school and of primary school) who have acquired a better understanding of the microscopic model are also able to explain the macroscopic phenomena more sufficiently.

\section{Conclusions}

The results of our research suggest that students of junior high school, and even younger students of primary school, can understand the microscopic model and are able to use this model to explain the macroscopic phenomena. Our research revealed that many students even of the $5^{\text {th }}$ grade seem to accept the idea of non-visible particles as constituents of matter and attempt to explain matters' properties and change of state based on their molecular structure. We also found correlation between students' microscopic and macroscopic explanations, supporting our view that the microscopic approach helps students achieve a better understanding of macroscopic concepts, reinforcing our theoretical framework whereby children form initial explanatory frameworks which differ from the scientific one and can be an obstacle in the educational process.

Our results are in accordance with other researchers [19], [20] who argue that this understanding of particulate theory helps students consolidate their initial understanding of matter (e.g. gaseous state, conservation of matter after continuous divisions, dissolution and melting, the difference between weight and density etc.) and provides an important basis for understanding other important concepts that cannot be easily approached without it it (e.g. evaporation and concentration, 
chemical change, the heat propagation models and the heat / temperature difference etc.).

Papageorgiou and Johnson [14] also argue that students' understanding of the changes of state is improved with the introduction of particulate ideas and Lofgren and Hellden [10] stress the need to link the knowledge about particulate structure of matter acquired by students in the school with everyday situations.

Our research adds to previous studies exploring the ways of improving the learning process and facilitating the understanding of the scientific concepts. The difficulty of many students to understand the scientific concepts is due to the fact that their initial explanatory frameworks are often ignored during teaching because many teachers believe that the new information provided to students can be easily incorporated into their existing framework. They do not realize that sometimes the existing knowledge can stand in the way, when the new information is not compatible with the existing [18].

Moreover, traditional curricula often underestimate the ability of students to develop the bases needed for the transition from the based on senses explanations to explanations based on the more abstract scientific concepts of the particulate theory of matter.

Our results suggest that the unifying model of microcosm can be a very useful tool for promoting the understanding of scientific concepts even in the 5 th grade.

\section{Acknowledgments}

The research was supported financially by the Foundation for Education and European Culture (Founders: Nicos and Lydia Tricha, Lysikratous 12, Athens 10558, Greece).

\section{References}

[1] Apostolakis E., Panagopoulou E., Savas S., Tsagliotis N., Makri V., Pantazis G., Petrea K., Sotiriou S., Tolias V., Tsagkogeorga A., and Kalkanis G., (2006). Official Science Handbooks for the 5th and 6th grade of Primary Education "Science - I Investigate and Discover", Greek Ministry of Education - Pedagogical Institute, Athens, 2006.

[2] Bouwma - Gearhart J., Stewart J., and Brown K., (2009). "Student Misapplication of a Gas-like Model to Explain Particle Movement in Heated Solids: Implications for curriculum and instruction towards students' creation and revision of accurate explanatory models". International Journal of Science Education, 31[9], pp. 1157-1174.

[3] Driver, E. Guesne, and Tiberghien, A., (1985). "Children's Ideas in Science”. Open University Press.
[4] Eshach H., and Fried M., (2005). "Should science be taught in early childhood?" Journal of Science Education and Technology, 14[3], pp. 315-336.

[5] Gikopoulou O., and Vosniadou S. (2012a). "Designing Learning Environments for Teaching Theory of Matter in Primary school". In Proceedings of the 8th International Conference on Conceptual Change, University of Trier

[6] Kalkanis G., (2013). "From the Scientific to the Educational: Using Monte Carlo Simulations of the microKosmos for Science Education by Inquiry”. Chapter in Book: Concepts of Matter in Science Education, editors Georgios Tsaparlis and Hannah Sevian, Springer.

[7] Kalkanis G., Gikopoulou O., Kapotis E., Gousopoulos D., Patrinopoulos M., Tsakonas P., Demitriadis P, Papatsimpa L., Mitzithras K., Kapogiannis A., Sotiropoulos D., and Politis S., (2013). "Physics through Experiments", official textbook for the $7^{\text {th }}$ grade, Ministry of Education, Institute of Educational Policy Computer Technology Institute and Press "Diophantus", Athens

[8] Kouka, A., (2000). "The concept of Water in Chemical Education: concepts, misconceptions, difficulties in understanding", (Unpublished doctoral dissertation), University of Ioannina, Chemistry Department, 2000.

[9] Lee, O., Eichinger, D.C., Anderson, C.W., Berkheimer, G.d., and Blakeslee, T.D., (1993). Changing middle school students' conceptions of matter and molecules, Journal of Research in Science Teaching, 30(3), 249-270

[10] Löfgren, L., and Hellden, G. (2009). A Longitudinal Study Showing how Students use a Molecule Concept when Explaining Everyday Situations. International Journal of Science Education, 31[12], 1631-1655.

[11] Merritt J., and Krajcik J., (2013). "Learning Progression Developed to Support Students in Building a Particle Model of Matter", Book Concepts of Matter in Science Education, Springer Series "Innovations in Science Education and Technology", Eds G. Tsaparlis and H. Sevian, Springer 2013, Vol. 19, p.11-45

[12] Nakhleh M., and Samarapungavan A., (1999), "Elementary school children's beliefs about matter", Journal of Research in Science Teaching, 36, p. 777-805

[13] Nussbaum J., (1985). "The particulate nature of matter in the gaseous phase". Chapter in R. Driver, E. Guesne, \& A. Tiberghien (Eds.) Book Children's ideas in science (pp. 124-144). Milton Keynes, UK: Open University Press.

[14] Papageorgiou, G., and Johnson, P. M., (2005). "Do particle ideas help or hinder pupils' understanding of phenomena?" International Journal of Science Education, 27[11], 1299-1317.

[15] Snir J., Smith C., and Raz G., (2003). "Linking phenomena with competing underlying models: A software tool for introducing students to the particulate model of matter". Science Education, 87, 794-830 
[16] Stavy R., and Stachel D., (1985). Children's ideas about "solid" and "liquid". European Journal of Education, 7, p. 407-421

[17] Vosniadou S., and Mason L., (2012). "Conceptual Change induced by Instruction: A Complex Interplay of Multiple Factors". In K.R. Harris, S. Graham \& T. Urdan (Editors-in-Chief), APA Educational Handbook. Vol. 2: Individual Differences and Cultural and Contextual Factors. American Psychological Association.

[18] Vosniadou S., Vamvakousi X., and Skopeliti E. (2008). "The Framework Theory Approach to the Problem of Conceptual Change" Chapter in S. Vosniadou (Ed.), International Handbook of Research on Conceptual Change (pp. 3-34). New York, NY: Routledge.

[19] Wiser M., Frazier K., and Fox V., (2013). "At the Beginning was Amount of Material: A Learning Progression for Matter for Early Elementary Grades", Chapter in Book "Concepts of Matter in Science Education", Springer Series "Innovations in Science Education and Technology", Editors Tsaparlis, Sevian, Springer Dordrecht Heidelberg New York London, Vol. 19

[20] Wiser M., and Smith C., (2008). "Teaching about matter in grades K-8: When should the atomic-molecular theory be introduced?" Chapter in International Handbook of Research on Conceptual Change, Edited by Stella Vosniadou 